\title{
Louis Sébastien Mercier, Néologie
}

Texte établi, annoté et présenté par Jean-Claude Bonnet, Paris, Belin, 2009, 598 p., ISBN 978-2-7011-4271-5, $26 €$

\section{Michel Biard}

\section{Q OpenEdition \\ 1 Journals}

Édition électronique

URL : https://journals.openedition.org/ahrf/11831

DOI : 10.4000/ahrf.11831

ISSN : 1952-403X

Éditeur :

Armand Colin, Société des études robespierristes

Édition imprimée

Date de publication : 1 juin 2010

Pagination : 263-264

ISBN : 978-2-200-92632-8

ISSN : 0003-4436

Référence électronique

Michel Biard, «Louis Sébastien Mercier, Néologie», Annales historiques de la Révolution française [En ligne], 360 | avril-juin 2010, mis en ligne le 01 juin 2013, consulté le 24 avril 2022. URL : http://

journals.openedition.org/ahrf/11831; DOI : https://doi.org/10.4000/ahrf.11831

Ce document a été généré automatiquement le 24 avril 2022.

Tous droits réservés 


\section{Louis Sébastien Mercier, Néologie}

Texte établi, annoté et présenté par Jean-Claude Bonnet, Paris, Belin, 2009, 598 p., ISBN 978-2-7011-4271-5, $26 €$

\section{Michel Biard}

\section{RÉFÉRENCE}

Louis Sébastien Mercier, Néologie, Texte établi, annoté et présenté par Jean-Claude Bonnet, Paris, Belin, 2009, 598 p., ISBN 978-2-7011-4271-5, $26 €$

1 Dans sa riche introduction, Jean-Claude Bonnet rappelle utilement le débat et les travaux sur la néologie au XVIII ${ }^{\mathrm{e}}$ siècle, du Dictionnaire néologique de Desfontaines (1726) au Dictionnaire critique de Féraud (1787-1788). Ce dernier, qui se présente pourtant comme un puriste, note dans sa préface qu'il intègre dans son travail quelque 2000 mots qui «se sont efforcés de s'introduire dans notre langue depuis vingt ans». Au même moment, Mercier, Rétif, d'autres encore, font œuvre de néologues et l'édition de 1798 du Dictionnaire de l'Académie illustre le chemin parcouru depuis la précédente (1762). Y apparaît notamment un "Supplément contenant les mots nouveaux en usage depuis la Révolution ». Néologue, Mercier l'a été, comme d'autres, dès avant celle-ci, ne serait-ce que dans son célèbre Tableau de Paris. Comme le souligne Jean-Claude Bonnet, « le piéton de Paris se montre un glaneur de mots impénitent, aussi attentif à ceux qu'il entend qu'à ceux qu'il découvre dans les affiches et les graffitis ». Dans sa Néologie, au mot « encachotés », Mercier écrit : «J'ai créé en 1789 l'expression d'Encachotés, qui fut copiée et répétée partout [...] Je me souviens qu'Encachotés produisit un formidable effet. Ce n'est pas d'aujourd'hui que je suis néologue, car je me suis plu à l'être dans tous mes écrits [...]».

2 Sa Néologie est publiée en 1801, mais l'origine en remonte au moins avant 1791. Il place sa publication sous le patronage de celui qui est alors considéré comme un héros républicain, son "collègue Bonaparte » («collègue », car tous deux sont membres de l'Institut). Cet hommage se retrouve d'ailleurs çà et là dans l'ouvrage, jusque dans la définition de «Représentation nationale » où Mercier se borne à recopier cette phrase 
de Bonaparte : « Nous voulons une république fondée sur la vraie liberté, sur la liberté civile, sur la Représentation nationale; nous l'aurons : je le jure, je le jure en mon nom et en celui de mes compagnons d'armes ». Citation attribuée au général, mais qui n'est donc accompagnée d'aucun commentaire...!

Le «petit dictionnaire de la Révolution » que Mercier a composé au fil des ans avec les mots du « lexique » révolutionnaire est éphémère à ses yeux, car « en politique [...] le jour d'hier est un cadavre ». Aussi, ce « lexique » étant jugé "volatile», il écarte de sa Néologie la plupart des mots qu'il avait notés et va jusqu'à ne retenir que 16 des 418 mots nouveaux du "Supplément» du Dictionnaire de l'Académie en 1798. Par ailleurs, loin de donner une définition à chacun des mots de sa Néologie, il préfère les illustrer par des extraits empruntés à d'autres auteurs, tel Bonaparte comme on l'a vu. Le Fonds Mercier de la BNF comprend justement une sorte de "bibliothèque manuscrite " composée de notes de lecture, de recueils d'éléments isolés, où Mercier a puisé la matière de sa Néologie. S'y côtoient Montaigne, Voltaire, Rousseau, Diderot, Rétif, mais aussi des hommes de la Révolution, tels Bonneville, Desmoulins, Grégoire, Mirabeau, etc. Comme le montre Jean-Claude Bonnet, derrière ces définitions qui n'en sont pas toujours, se dessine également un autoportrait de Mercier, la satire servant alors à envoyer des piques à ceux qu'il n'aime point. Cela explique, fût-ce en partie bien sûr, l'accueil plutôt mauvais réservé au livre en 1801.

Quant aux mots de cette Néologie, chaque lecteur pourra à sa guise errer de l'un à l'autre, et souvent s'amuser de l'humour de Mercier (« Accostable: Voltaire, dans son château, était plus accostable que J.-J. Rousseau dans son grenier»). Ceux qui s'intéressent à la Révolution française n'y trouveront point tous les mots nouveaux alors créés, mais ils se consoleront sans peine avec les commentaires partisans accolés à « agitateur» (celui qui trompe le peuple); « anarchiser » (les ennemis de la France ont, pour ce faire, "créé, soudoyé, encouragé les anarchistes»); "anguillomeux» (où l'anguille renvoie à La Fayette); «apâteur» (appliqué aux royalistes); " corruptionner » (un seul "mauvais livre » peut «corruptionner» un peuple, ce qui fait trembler tout défenseur de la liberté de la presse); "fuyardes» (les tantes de Louis XVI); «liberticide » (tout moyen employé par les ennemis de la République, la plume, le sabre ou le crucifix); "fournée » (qui permet de mentionner le sort des Girondins); «mangeurs » (« un paysan de Montrouge, plein de bon sens, appelait la Révolution française le combat des Mangeurs et des Mangés »); "tigreux » (comme Néron, mais «il n'est pas le seul, hélas!»); "vandalisme» (rapporté aux seuls «montagnards de la sainte montagne»...); etc. Certains mots auraient pu être accompagnés par davantage d'explications en notes (les «formes acerbes» qui renvoient à un discours de Barère à propos des exécutions faites sous l'autorité du représentant du peuple en mission Le Bon; la « queue » de Robespierre qui a fait naître toute une campagne de presse...), mais c'était là demander un tout autre travail, aussi l'indulgence est-elle de rigueur.

5 Pour accompagner le texte, Jean-Claude Bonnet nous offre, outre l'introduction dont la richesse a été mentionnée, une précieuse liste des auteurs et des œuvres cités par Mercier, classés par ordre chronologique et renvoyant aux entrées (hommes et écrits de la période révolutionnaire témoignent notamment des sympathies politiques de Mercier); deux brefs projets manuscrits qui évoquent la méthode de l'auteur; deux longs comptes rendus publiés à l'automne 1801 dans le Mercure de France et La Décade (...); enfin, deux chronologies très utiles, l'une permettant de se repérer dans la 
«querelle » néologique au XviII ${ }^{e}$ siècle, l'autre dans la vie et l'œuvre de Mercier. Les Éditions Belin nous proposent donc, grâce aux talents et aux connaissances de JeanClaude Bonnet, une très belle et rigoureuse édition scientifique de cette Néologie. Laissons la conclusion au mot " amatrice ", avec un éternel débat à la clef : «l'Académie ne crée pas les mots; son emploi est d'enregistrer ceux que l'usage autorise. Un mot est donc français avant qu'il soit inséré dans son Dictionnaire [...] ». 